\title{
MANNer Modification OF States
}

\author{
Wilhelm Geuder, \\ Universität Konstanz / SFB 471 \\ wilhelm.geuder@uni-konstanz.de
}

\begin{abstract}
In a recent contribution to a long-standing discussion in semantics as to whether the neoDavidsonian analysis should be extended to stative predicates or not, Maienborn $(2004,2005)$ proposes to distinguish two types of statives; one of them is said to have a referential argument of the Davidsonian type, the other not. As one of her arguments for making such a distinction, Maienborn observes that manner modification seems to be supported only by certain statives but to be excluded by others (thus linking the issue to the use of manner modification as one major argument in favour of event semantics, cf. Parsons 1990). In this paper, it is argued that the absence of manner modification with Maienborn's second group of statives is actually due to a failure of conceptual construal: modification of a predicate is ruled out whenever its internal conceptual structure is too poor to provide a construal for the modifier; hence, the effects observed by Maienborn reduce to the fact that eventive predicates have a more complex conceptual substructure than stative ones. Hence, the issue of manner modification with statives is shown to be orthogonal to questions of logical form and event semantics. The explanatory power of the conceptual approach is demonstrated with a case study on predicates of light emission, adapting the representation format of Barsalou's (1992) frame model.
\end{abstract}

\section{Introduction}

\subsection{General Background: Neo-Davidsonian Semantics}

This paper is about the interpretation of manner modifiers and its implications for the neoDavidsonian framework of semantics (cf. e.g. Parsons 1990). The neo-Davidsonian theory rests on two major pillars, one semantic and one ontological. Semantically, it is a theory of the logical form of sentences which is based on the idea that logical form involves predication and quantification over event variables. In particular, manner adverbs (A) modifying a verb (V) are analysed via joint predication of the event variable, hence manner modification is represented via a conjunction of the form: $V(e) \& A(e)$. This is, of course, the standard pattern of intersective modification that is also posited for nouns and adjectives when they predicate of concrete individuals.

The ontological aspect of the theory is that events are seen as particulars in the world; they are not abstract objects in the way facts or properties are. Some consequences which ensue from this view are pointed out by Maienborn (2004, 2005):

a. Eventualities are perceptible.

b. Eventualities can be located in space and time.

c. Eventualities can vary in the way that they are realized.

The third point might require some explanation. For one thing, it reflects the fact that events, being particulars, occur as instantiations of a type, i.e. the event property denoted by some verb. Another aspect implicit in (1c) is that predicates of events allow manner modification; 
in this way, instantiations of an event type give rise to subtypes. When this happens, "the way in which events are realized" can be characterised via some sort of conceptual content, i.e. the "manner" of an event.

Before a neo-Davidsonian semantics can be put to work, of course, it is necessary to know precisely which types of predicates have a neo-Davidsonian argument and which ones do not.

\subsection{Events and States}

Parsons (1990), and many semanticists after him, distinguish two sorts of "eventualities" (i.e. events in a broad sense), namely events proper and states. However, other authors have denied that states should be treated as Davidsonian individuals, beginning with Davidson (1967) himself. On this second view, stative verbs and adjectives would not have referential e-arguments (a view that has also been elaborated and defended by Katz (2000, 2003), and others).

In this connection, Maienborn (2004) has recently proposed that there are actually two types of "states": certain stative predicates refer to a neo-Davidsonian entity (called "D-states" by Maienborn), others refer to an abstract entity (which she calls "K-states", i.e. "Kimian states" after Kim (1976), who proposed to explain events as basically a propositional type of entity). From the background of the characterisation of events in (1), Maienborn (2004) adduces a number of empirical effects as supporting her distinction:

a. "Eventuality expressions can serve as infinitival complements of perception verbs".

Ich sah Bardo schlafen.

(I saw B. sleep(ing))

* Ich hörte das Radio laut sein. ～(I heard the radio be(ing) loud)

b. "Eventuality expressions combine with locative and temporal modifiers."

Die Perlen glänzen in ihrem Haar. (The pearls are gleaming in her hair)

* Das Kleid ist auf der Wäscheleine nass. (The dress is on the clothes-line wet)

c. "Eventuality expressions combine with manner adverbials, instrumentals, comitatives, etc."

Bardo schläft friedlich/mit seinem Teddy/ohne Schnuller.

(Bardo is sleeping \{peacefully / with his teddy / without dummy\})

* Bardo war friedlich/mit seinem Teddy / ohne Schnuller müde.

(Bardo was tired \{peacefully / with his teddy / without dummy\})

The examples in (2c) show an asymmetry with respect to manner modification, supposedly establishing two subtypes of stative predicates, and this is the phenomenon that the present paper is centred on. I want to argue in this paper that the peculiar behaviour of (certain) statives with respect to manner modification is actually not related to a distinction in terms of different sorts of external arguments, and that it cannot (directly) be used to determine the range of application of the neo-Davidsonian analysis.

Rather, I want to show that the crucial factor which governs the applicability of manner modifiers is the conceptual complexity of the property expressed by a verb or an adjective. To this end, verb meanings will be decomposed into a richer conceptual structure, consisting of property values and sorted in conceptual dimensions; manner modifiers then typically have the effect of restricting the admissible property values of one dimension. 


\section{Manner Modification: Beyond Event Predication}

The striking thing about the examples seen in (2) above is that verbs and adjectives may behave differently with respect to the licencing of modifiers, in spite of being fairly similar in meaning. It should be made clear, however, that the distinction at issue here is not tantamount to the categorial distinction between verbs and adjectives (even though the selection of examples given in (2) might suggest this). For one thing, there are verbs in Maienborn's data that pattern with the "K-states" (e.g. wissen / know or wiegen / weigh(intransitive)). For another, it seems that there are a few predicative adjective constructions in German which denote events and pattern with eventive verbs in the perception verb construction (e.g. German behilflich sein, which as far as I can tell means exactly the same thing as the verb helfen and English help, and behaves in the same way according to the tests - all this in spite of the adjectival derivational affix -lich).

Therefore, a truly semantic explanation is needed for the differences with respect to modification. Any such explanation will have to posit that similarities of meaning, as between sleep and tired, are actually misleading and that there are subtle semantic factors which make a decisive difference. As already outlined, Maienborn (2004) offers the explanation that the distinction is related to the fact that adjectives like müde / tired do not refer to events (e), but to abstract "property exemplifications" (of a sort k, i.e., "Kimian states"). Apparently, then, the modifiers in the problematic cases would not be able to accomplish exactly this kind of predication:

$$
\begin{array}{ll}
\text { sleep }(\mathrm{e}) \& \operatorname{peaceful}(\mathrm{e}) & \text { (to sleep peacefully) } \\
\operatorname{tired}(\mathrm{k}) \& * \text { peaceful(k) } & \text { (to be tired peacefully) }
\end{array}
$$

However, there are some immediate objections that can be raised against this sort of approach. For one thing, it seems that the effect is not strong enough for the predicted sortal mismatch. Consider the following attempts at predicating the adjective "peaceful" of different sorts of entities:

$$
\begin{array}{lll}
\text { Event: } & \text { peaceful(e) } & \text { John is sleeping peacefully } \\
\text { "K-state": } & \text { peaceful(k) } & \text { ? John is peacefully tired } \\
\text { Fact: } & \text { peaceful(f) } & * \text { The fact that John is tired is peaceful } \\
\text { Proposition: } & \text { peaceful(p) } & * \text { It is true, and it is peaceful, that John is tired }
\end{array}
$$

Truly abstract entities are found to produce a deviance that is markedly more profound. To save the idea of a sortal mismatch, one would have to posit that abstractness is a matter of degrees and that this makes K-states produce relatively weaker deviations.

However, a second objection is that the clear contrast in perception verb constructions, another diagnostic for the K-/D-distinction with states, does not align with the patterning of modifiers. In (5), it can be seen that we get clear differences between verbal and adjectival expressions for various kinds of "being open" in German:

a. offen sein $\approx$ offenstehen

?? Ich sah die Türe offen sein ${ }^{\text {ok }}$ Ich sah die Türe offen stehen
(I saw the door be open)

(I saw the door stand(ing) open)

b. offen sein $\approx$ klaffen

$$
\begin{array}{ll}
\text { ? Ich sah da eine Lücke offen sein } & \text { (I saw a gap be open) } \\
{ }^{\text {ok }} \text { Ich sah da eine Lücke klaffen } & (\sim \text { I saw a gap yawn(ing) })
\end{array}
$$


c. offen haben $\approx$ aufsperren

? Ich sah ihn den Mund offen haben (I saw him have his mouth open)

${ }^{\text {ok }}$ Ich sah ihn den Mund aufsperren ( I saw him have his mouth (wide) open)

In spite of these clear contrasts, modifiers are applicable in the very same way. For instance the asymmetry shown in $(5 \mathrm{c})$ above cannot be replicated with modification data:

a. weit "wide":

Er hatte den Mund weit offen / Er sperrte den Mund weit auf

b. locker "slack, relaxed"

Er hatte den Mund locker offen / \# Er sperrte den Mund locker auf

While in (6a) the adverb wide is able to modify both predicates, there is a deviation in (6b) with the supposed K-state - however, it is of an interesting kind: the sentence Er sperrte den Mund locker auf is felt to be contradictory. This, however, shows that the modifier locker is semantically applicable, because otherwise the contradictoriness of its contribution could not be ascertained. This is to say, the word meaning of the verb aufsperren contains a component that is the opposite of locker: it is a manner of keeping one's mouth open with the application of some force.

This is a simple example for why conceptual explanations may be needed to rule out deviant modification structures, and it provides an initial motivation to investigate how far such conceptual explanations can be carried, and how they can be formulated, to begin with.

\section{Conceptual Structure}

\subsection{A Simple Example: Colours and Colour Terms}

\subsubsection{Feature Dimensions}

As a first approach to an analysis of conceptual structure, let us have a brief look at a fairly narrow and well-understood conceptual domain, namely colours, taking up a recent proposal of conceptual modelling by Gärdenfors (2000). Colours involve three perceptual parameters: hue, brightness, and saturation. Each of these can be represented as an array of values, depicted below as arrays of points; in reality, however, the degrees of brightness, saturation, and the hue values must be continuous scales. Following Gärdenfors (2000), I will call each of these scales a property (in a narrow sense); it is made up of property values.

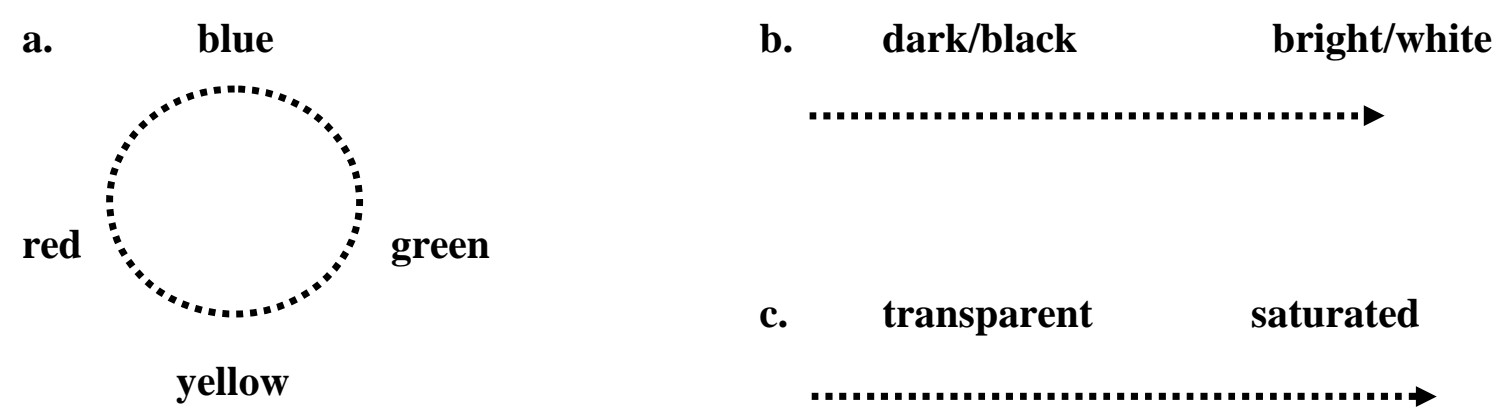

Gärdenfors (2000) proposes to represent the internal structure of the conceptual domain "colour" as a unified quality space, with hue, brightness, and saturation as its three 
dimensions. A particular colour concept, e.g. "green", would then correspond to a coherent region in such a 3D-space. It would involve the hues around the "prototypical green" in (7a); a medium range of brightness values from $(7 \mathrm{~b})$, coupled with a range of saturation values from (7c) that at least excludes the transparent end of the scale.

However, as argued in detail by Geuder \&Weisgerber (2005), a literally geometrical representation in terms of a unified metrical space is not a generally viable technique for the representation of concepts of all kinds, even though it does seem to work for colours and other simple properties. Therefore, let me use a more abstract representation that takes up the idea of having separate tiers ("feature dimensions") which are made up from property values.

Let us say that the conceptual substructure of a predicate $\mathrm{P}$ provides sets $\mathrm{Q} 1, \mathrm{Q} 2, \ldots$, Qn, called the conceptual dimensions of $\mathrm{P}$, such that each $\mathrm{Q}$ is made up of a number of mutually incompatible property values:

$$
\begin{aligned}
\mathrm{P}: & <\mathrm{Q} 1=\{\mathrm{q} 1 \mathrm{a}, \mathrm{q} 1 \mathrm{~b}, \mathrm{q} 1 \mathrm{c}, \ldots\}, \\
& \mathrm{Q} 2=\{\mathrm{q} 2 \mathrm{a}, \mathrm{q} 2 \mathrm{~b}, \mathrm{q} 2 \mathrm{c}, \ldots\}, \\
& \mathrm{Q} 3=\{\mathrm{q} 3 \mathrm{a}, \mathrm{q} 3 \mathrm{~b}, \mathrm{q} 3 \mathrm{c}, \ldots\}, \ldots>
\end{aligned}
$$

For the colour "green" as an example, we would have the substructure Q1 x Q2 x Q3, which can be characterised as follows:

green:

$<$ QHUE $=\{\ldots, \mathrm{q} 1 \mathrm{a}, \mathrm{q} 1 \mathrm{~b}, \mathrm{q} 1 \mathrm{c}, \ldots\}$ (a set which includes the various "green" hues), QBRIGHTNESS $=\{\ldots, \mathrm{q} 2 \mathrm{~b}, \mathrm{q} 2 \mathrm{c}, \ldots\}$ (brightness values, excluding at least the extrema "black" and "white"),

QSATURATION $=\{\ldots \mathrm{q} 3 \mathrm{~b}, \mathrm{q} 3 \mathrm{c}, \ldots\}$ (excluding at least the extreme values in the region "fully transparent") >

While in this particular case, an ordering can be imposed on the values, this need not be the case in general.

\subsubsection{Modifiers}

Let us now see how this simple model can be used to account for modification. The idea in Gärdenfors (2000) is to see modification as an operation that restricts the allowed range of property values of a concept in (at least) one dimension. Indeed, it appears that the modifiers which can appear with colour terms can be sorted into the dimensions outlined above:

$$
\begin{array}{lll}
\text { blaugrün } & \text { hellgrün } & \text { blassgrün } \\
\text { blueish green } & \text { bright green } & \text { pale green }
\end{array}
$$

Here is a sketch of how the modification operation works. Let us consider the example hellgrün ("bright / light green"). The modifier hell is indexed for the quality dimension "brightness" and hence targets only the brightness dimension of the modified concept "green", leaving its other dimensions unchanged.

(11) a. hell QBRIGHTNESS $=\{\ldots, \mathrm{hw}, \mathrm{hx}, \mathrm{hy}, \mathrm{hz}\}$

b. grün $<\mathrm{QHUE}=\{\ldots, \mathrm{ga}, \mathrm{gb}, \mathrm{gc}, \ldots\}$,

$$
\begin{aligned}
& \text { QBRIGHTNESS }=\{\ldots, \mathrm{q} 2 \mathrm{~b}, \mathrm{q} 2 \mathrm{c}, \ldots\}, \\
& \text { QSATURATION }=\{\ldots \mathrm{q} 3 \mathrm{~b}, \mathrm{q} 3 \mathrm{c}, \ldots\}>
\end{aligned}
$$

c. hell (grün)

$<$ QHUE - unchanged, 


\section{QBRIGHTNESS = QBRIGHTNESS(hell) ^QBRIGHTNESS(grün),} QSATURATION - unchanged >

While this account of modification targets property values, it is equivalent to the familiar view of modification as intersection of extensions. This is so because the feature values on each dimension are mutually exclusive, so every object in the extension of a predicate must have exactly one value in each dimension. Consequently, all n-tuples of values from $Q 1 \times Q 2$ $x \ldots x Q n$ are mapped onto disjoint sets of objects, and every operation that restricts the set of admissible feature values has the same effect on the extension of the predicate.

\subsubsection{Manners vs. Degrees}

Given that the modification operation just described involved scales of ordered feature values, there is some similarity with degree modification, and some remarks are in order as to the distinction between subsective modification and degree modification. It is not immediately clear whether the instances discussed above should be called "manner modification", but manner modifiers can in any event be grouped with other typical intersective modifiers and contrasted with degree modifiers.

Obviously, degree scales are based on a decomposition of properties into feature values, too. In modifying the property scales that form the dimensions of colour concepts, however, we used modifiers which themselves had a conceptual content in terms of a property scale. This, then, is a first difference to degree modification: Degree modifiers carry an abstract specification for regions on arbitrary property scales, e.g. very denotes the upper end of any degree scale. Therefore, degree modification involves an additional step of mapping from a set of feature values onto an abstract scale of degrees, and degree modifiers operate on the latter.

Moreover, it could be seen that we were dealing with modifiers that applied to "multidimensional" conceptual structures, and these are exactly the ones that are hard to combine with degree modifiers. This difference is expected because modifiers that are indexed for some particular conceptual domain will be able to retrieve their designated domain when applied to a larger conceptual structure in the process of modification. For degree modifiers to work, however, we need a predicate that denotes one single scale, i.e. a property (in the narrow sense). It is possible to force the application of degree adverbs to complex concepts, for instance, in German we find clear cases of degree modification with verbs (cf. Stamm 2005). Either we have to formulate specific conditions as to the accessibility of particular gradable meaning dimensions inside a complex concept, a particular type of prominence that makes a conceptual dimension accessible for simple degree modifiers; or we have to formulate a mechanism that is able to map the whole concept onto a scale (say, a scale of intensity), and apply the degree modifier to this derived scale. In any case, the distinction between degree and intersective / manner modification remains intact.

As a last aspect of this distinction, we cannot reasonably suppose that all property dimensions of arbitrary concepts will always involve a scale of ordered values, although this was the case with the three dimensions of colour. The mechanism of restricting sets of feature values sketched in 3.1.2 above is also available for property dimensions without scalar ordering, while degree modification cannot apply in such a case. This is the case with the more complex concepts that I am now turning to.

\subsection{Predicates of Light Emission}

In this section, the conceptual approach will be applied (with modifications and extensions) to a set of examples that are more crucial for Maienborn's (2004) argument that certain statives do not show effects of an event argument. Consider her example (12a) along with the 
contrasting examples $(12 b-c)$ :

a. Die Perlen glänzten matt / rötlich / feucht

(The pearls were gleaming + modifiers: dull / reddish / moist)

b. Das Licht war ?? feucht hell / ?? rötlich hell

(The light was moistly / reddishly bright)

c. Die Lampe leuchtete hell / rötlich / ?? feucht

(The lamp was shining brightly / reddishly / moistly)

Example (12b) (not provided by Maienborn) contrasts with (12a) in the same fashion as the group of examples introduced earlier in (2c): glänzen (gleam, glow) allows a whole range of modifiers while the adjective hell (bright) does not admit any of them. In spite of the neat contrast between (12a) and (12b) it can already be seen that there is no clear-cut division between just two types of predicates: the verb leuchten (shine (intr.)) allows some of the modifiers that may appear with glänzen, but not others. This calls for an examination of the conceptual interpretations in more detail.

\subsubsection{Re: (12b) Das Licht war ?? feucht hell / ?? rötlich hell}

Example (12b) can already be understood on the basis of what has been said in the section on colour concepts above. Modification fails because the conceptual substructure of hell (bright) is a simple scale and does not provide isolable property dimensions that manner modifiers could target inside it. There is a slight complication here in that the construction rötlich hell is not immediately judged as deviant by many German speakers, but this is arguably due to interference with a compound rötlich-hell which does not have rötlich (reddish) as a modifier but rather means "reddish and bright", thus not modifying the brightness value itself. This interpretation is irrelevant to the point at hand, however.

\subsubsection{Re: (12c) Die Lampe leuchtete hell / rötlich (The lamp was shining brightly / reddish)}

With the analysis of the concept leuchten / shine we get to cases that do not yield easily to a description in terms of orthogonal feature dimensions, which is one of the things that speak against Gärdenfors' (2000) geometrical interpretation of the conceptual decomposition (in addition to the points raised in Geuder \& Weisgerber 2005).

Many concepts require an analysis with a richer structure in which the conceptual dimensions are linked via additional relations and constraints. Such structures have been described e.g. in the frame theory of Barsalou (1992). A first inspection of the model in Barsalou (1992) shows that some of the "relational links" which his model provides correspond to aspects of the model already given in section 3.1 above. In particular, Barsalou's "TYPE" relation mirrors the relation between conceptual dimensions and their property values, i.e., the "TYPE" relation serves to split a concept into mutually exclusive values that implement it. A further relation which Barsalou calls "ASPECT-OF" is what serves to couple a set of (what we have called) "dimensions" to form a concept. This structuring is thought to be recursive, however: a concept may be decomposed into sub-concepts which themselves exhibit a decomposition into quality dimensions.

A comprehensive review of frame theory is clearly beyond the scope of this paper, and for the present purpose, it will suffice to adapt its major ingredients into a simplified representation. However, a weakness of the system in Barsalou (1992) which must be pointed out is that the "ASPECT-OF" link serves as a cover term for a whole number of different relations without reflecting any further differences. In particular, it treats conceptual dimensions of verb 
meanings on a par with participant roles. In my representation of the verb leuchten / shine, I will therefore annotate the structure with functor-argument relationships. Hence, the meaning of leuchten will be decomposed basically as "(for a source) to emit light", with the appropriate "ARGUMENT" links between these two aspects of the concept, plus a some sub-aspects of each of the main constituents that can be easily identified. The component "light" makes recourse to the concept "colour" which has already been analysed.

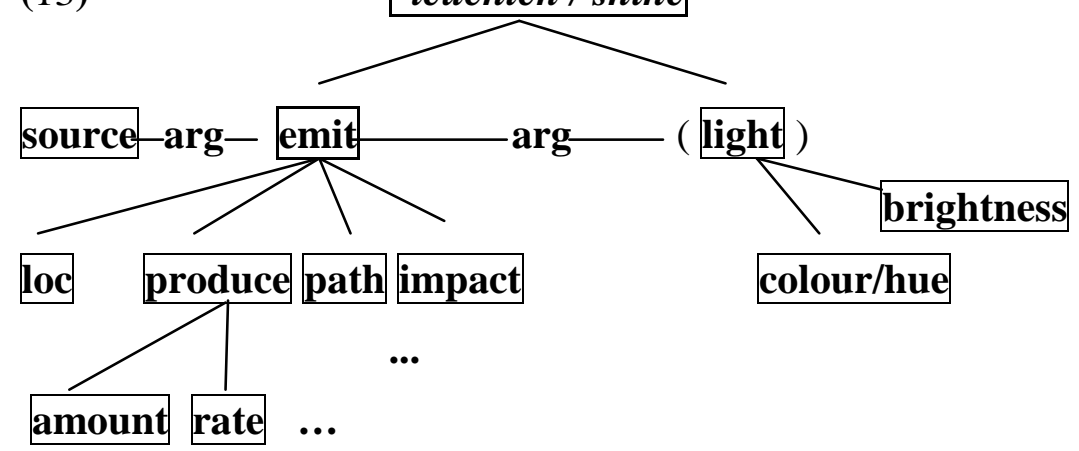

The conceptual constituent related to "emission" will minimally have to involve the characterisation of a process of light production, a path of the light emitted and a characterisation of what happens at the endpoint ("impact", e.g. visibility). Obviously, the argument relation that connects "emit" with "light" has to be inherited by the subconcepts of "emit". The component "light" functions as an argument, it is true, but does not surface in the argument structure of the verb; therefore it is simultaneously classified as a conceptual dimension (more on this topic below).

Without going too far into the details of conceptual knowledge that are implicit in this decomposition, let me point out that many modifiers can be easily identified as pertaining to specific sorts of sub-concepts or property values:

\section{hell leuchten (shine brightly) : BRIGHTNESS}

rot leuchten (shine red) : COLOUR/HUE

konstant leuchten (shine constantly) : PRODUCE: RATE

schwach leuchten (shine weakly) : PRODUCE: AMOUNT \& IMPACT

In this way it becomes clear why the verb leuchten / shine supports more modifiers than hell / bright: the reason is its greater conceptual complexity. Since leuchten includes the conceptual dimension of hell, modifiers of the latter carry over to the former.

\subsubsection{Re: (12a) Die Perlen glänzten matt / rötlich / feucht (The pearls were gleaming + modifiers: dull / reddish / moist)}

As a next step, let us consider the conceptual structure of glänzen /gleam, which involves an additional degree of complexity. First of all, we can observe that nearly all the modifiers that were found to combine with the verb leuchten / shine are found here again: we get hell glänzen, rot glänzen, schwach glänzen, in parallel to the data in (14). This indicates that glänzen / gleam should incorporate much of the conceptual structure of light emission concepts.

An intriguing case, however, is the use of the adjective feucht (moist, wet) as a modifier. Note the contrast between glänzen and leuchten in this respect:

\section{(15) Die Perlen glänzten feucht}

?? Die Kugel leuchtete feucht (the pearls gleamed wet)

(the sphere shone wet) 
This contrast can be explained as being due to a meaning component of glänzen that makes reference to properties of a surface and which is absent from leuchten / shine. To see this, note that feucht as a modifier can only be construed with respect to a surface in this example, although other construals would be allowed by the lexical meaning of the adjective. A log of wood, for instance, can be said to be feucht when it is soaked through with moisture. However, in (16) this construal is excluded:

Das Holz glänzte feucht

(the (piece of) wood gleamed wet)

Here, we must be dealing with a situation in which there is water on the surface (it is easier to imagine a piece of wood with a varnished surface, which is wet), not with a piece of wood which is damp and rotten and at the same time has a varnished surface which is gleaming in the sun. How do we know that feucht may only refer to a property of a surface when it modifies glänzen? The reason must be that the verb does not provide for any other way of linking the modifier to the situation frame. This demonstrates that the notion of a surface is accessible from the verb meaning. And the reason for this is the specific way in which glänzen / gleam specidies a concept of light emission: it is light emission by reflexion at a surface. Here is a sketch of the relevant parts of the situation frame:

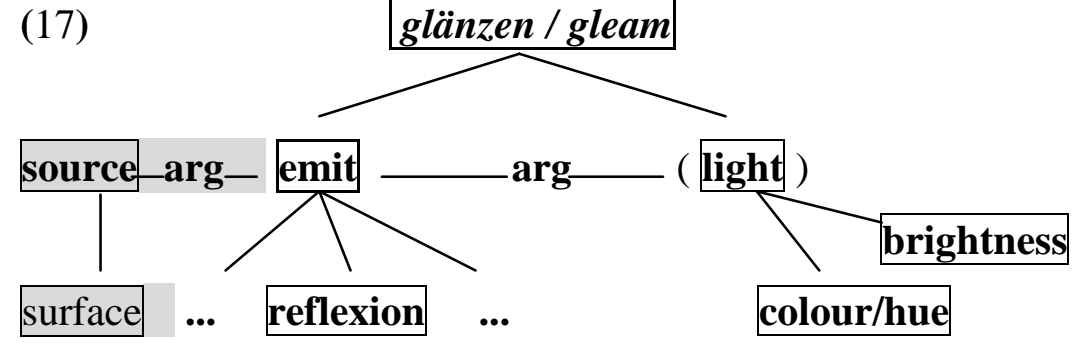

If we say that there is a "surface" feature which licences the application of the modifier feucht, however, we are running into new problems, because not any adjective that is applicable to surfaces can become a manner adverb; for instance we don't get zerkratzt or schmutzig glänzen (gleam + modifiers "scratched /dirty"). And more generally, one might raise the question of how the content of such conceptual representations is to be kept within bounds, and how endless chainings of world knowledge can be avoided: do all kinds of conceptual knowledge that are related to surfaces have to be included in (17) as well?

I propose that, indeed, we need a fixed, and selective, representation of that part of conceptual information that may interact with the semantics. Let us make the general stipulation that event concepts do not automatically inherit the conceptual dimensions of the possible referents of their argument roles - only if a predicate specifies implicit argument roles does their sortal information count as part of the predicate's meaning. This stipulation is also needed to secure the conclusion from the discussion surrounding (16) above: the alternative interpretation which was found unavailable for (16) (a log of wood soaked through with moisture and gleaming for some other reason) would actually correspond to a simple predication of feucht / moist on the subject of the sentence. Therefore, we generally have to exclude a construal of modifiers as simply predicating of the subject argument. Arguably, this predicational relationship is only possible in a different grammatical construction, namely a depictive construction. (See Geuder 2004 for details about the semantic delimitation between depictives and adverbial modifiers, and Geuder (2000, ch. 3) for further substantiation of the claim that manner modifiers exclude predication of a syntactic argument but can be licenced by implicit argument roles).

These considerations lead to the conclusion that the shadowed part in (17) is not a possible target for a manner modifier. If this is true, the mechanism of modification in the example feucht glänzen must be of a different kind than the one in (13-14). We are led to the conclusion that one of the core conceptual dimensions must undergo modification, not just the 
"source / surface" part.

The solution to this problem is that, this time, the modifier applies in an indirect fashion technically, by invoking what is called a CONSTRAINT in Barsalou (1992), i.e. a correlation between values which is part of the knowledge base. The very concept of "reflexion of light at a surface", which is at the heart of the meaning of glänzen / gleam, involves knowledge about a correlation between properties of a surface and corresponding qualities of the light emitted by it. To begin with, the surface has to have a certain smooth texture for reflexion to be possible at all, and moreover particular materials, such as water, are associated with their own characteristic pattern of light reflexion. This piece of knowledge must enter into the calculation of the conceptual interpretation of the modifier.

Let us invoke an additional attribute "radiance" in the representation below to capture more differences in the qualities of the light emitted:

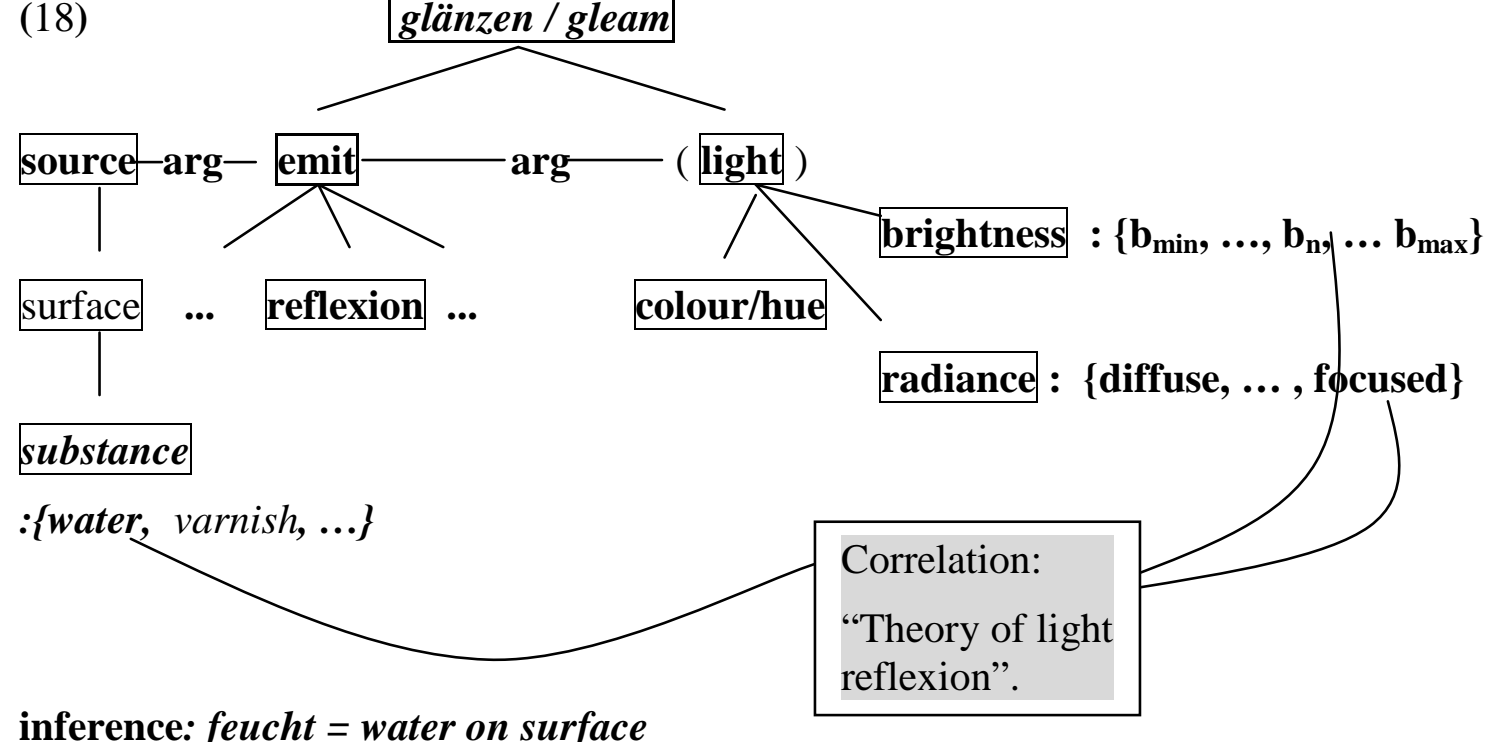

As I have said, manner modification must involve one of the core conceptual dimensions of glänzen. This is indeed possible due to the correlation of "radiance" and probably "brightness" with properties of surfaces - provided that an inference is added that the predication by the modifier feucht concerns a surface. Via the said correlation, this modifier then effects a restriction of property values in the "radiance" and "brightness" dimensions, and thus indirectly targets the conceptual core of glänzen, even though it does not bear a lexical specification that targets these conceptual dimensions.

Let us sum up the findings concerning the indirect restriction of an event property, in which properties associated with entities external to the event concept plus a constraint on correlations of property values yields a restriction on event-internal property values. The shifted interpretation of an adjective A, for application as a modifier to an event concept $\mathrm{C}$ then derives as follows:

(19) $\operatorname{MANNER}_{(\mathbf{C})}(\mathrm{A})$ is a set $\mathrm{S}$ of property values q such that for some $\mathrm{a} \in \mathrm{A}$ :

$\exists \mathrm{Q}$ in $\mathrm{C}$ with $\mathrm{q} \in \mathrm{Q}$, and GEN $[\mathrm{a}(\mathrm{x}) \Rightarrow \mathrm{q}(\mathrm{e})]$ (for some $\mathrm{x}$ )

Interpretation:

$\operatorname{MANNER}_{(\mathbf{C})}(\mathrm{A})(\mathrm{C})$, with $\mathrm{Q}_{\mathbf{1}}, \ldots, \mathrm{Q}_{\mathbf{n}}$ as the conceptual dimensions (attributes) of C: $=$ the structure $C$ with $S \cap Q_{i}$ replacing $Q_{i}$, unchanged elsewhere. 


\subsection{D-States}

We have now arrived at a fairly elaborate view on how manner modification may be governed by the conceptual complexity of verb meanings. Naturally, all that could be done here is to lend this claim some credibility; there is no proof in the strict sense, because the argumentation would be complete only after in-depth analyses have been conducted of each single verb type and its modifiers.

In order to provide some further substantiation for the conceptual approach to manner modification, let me now sketch an account for the intriguing contrasts uncovered by Maienborn (2004, 2005) which concern "minimal pairs" such as the following (partly taken from Maienborn, with contrasting examples added to (20b-c):
a. Bardo schläft friedlich.
(B. is sleeping peacefully)
* Bardo war friedlich müde
(B. was peacefully tired)
b. Carolin saß reglos am Tisch.
(C. sat motionless at the table)
?... war reglos aufrecht
(? C. was motionless upright)
c. $\quad *$ Carolin war geduldig durstig
(* C. was patiently thirsty)

Carolin schmachtete geduldig in der Hitze

(roughly: C. was patiently suffering / parched in the heat)

These examples show manner modification with "D-states", i.e. Maienborn's "eventive" subtype of states. I think it is important to observe that all these modifiers form a coherent semantic class — they speak about "things not happening":

$$
\begin{array}{lll}
\text { friedlich } & \text { peaceful } & =\text { "without disturbance" } \\
\text { reglos } & \text { motionless } & =\text { "without moving" } \\
\text { geduldig } & \text { patient } & =\text { "without losing calmness / without change of attitude" }
\end{array}
$$

Accounting for these cases requires a new property dimension, which I would like to identify as "the continuation / termination conditions for a state". Hence, we are dealing here with a feature that is to some extent a dynamic, hence eventive, feature. While this feature is not dynamic in the sense of asserting change, it speaks about potentials of change. A device for representing this is already in place in the framework of Barsalou (1992), namely a link of the type "STATE". This relation serves to specify property values (of object concepts) which cooccur in an event because they appear in a sequence. The particular pattern of sequencing itself is stated separately as a conceptual dimension of its own. Consider the following sketch of the concept schlafen / sleep:
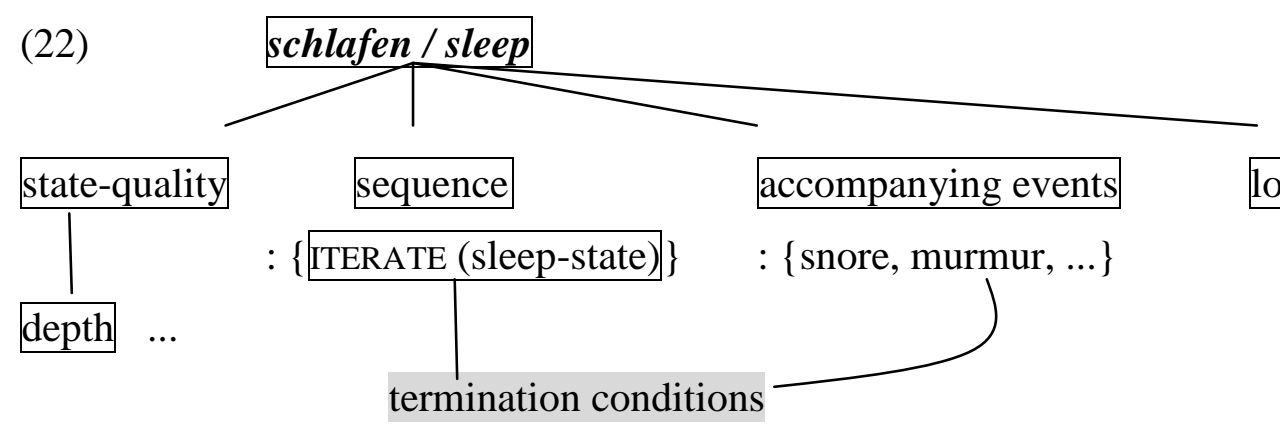

In this representation, Barsalou's "STATE" link has been rewritten as an iteration instruction, since we are dealing with a succession of states of the same type. The basic idea is then that event and state concepts may specify termination conditions: it is certainly part of our conceptual knowledge about sleeping that it is terminated by waking up. We can now begin to 
understand the meaning of the modifier friedlich / peaceful via a correlation between termination conditions and accompanying events of sleeping: the modifier indicates "absence of disturbance", i.e. there are no accompanying events of a kind that could trigger, or come close to triggering, termination of the situation.

The introduction of a conceptual dimension of iteration / termination conditions should suffice to indicate the direction of an analysis; however, for reasons of space, this cannot be elaborated in more detail in this paper. In sum, however, it seems to me that this type of attribute is at the core of Maienborn's $(2004,2005)$ distinction between "event-like" and "property-like" statives. It should have become clear that this distinction can be modelled without making recourse to different types of referential arguments.

At the same time, however, it would not seem to be incompatible with Maienborn's analysis: predicates referring to abstract objects may well turn out to have a poorer conceptual structure than concrete, eventive predicates. The sortal distinction would then be in parallel to the differences in conceptual structures. In the first place, therefore, the conclusion to be drawn is that the the analysis of manner modification is independent of the issue of neo-Davidsonian arguments with statives. The argument that predicates lack an event argument because they do not support (certain) manner modifiers is not valid.

\section{Conclusions and Outlook}

In the preceding sections, the restrictions on how various verbs and adjectives select their modifiers have been derived from the conceptual content of the predicates in question. I have defended the thesis that it is the factor of conceptual complexity which determines the range of modification options. If a group of predicates is observed to allow fewer modifiers than others, this can therefore be seen as pointing to a smaller conceptual complexity.

We are then led to the expectation that what Maienborn $(2004,2005)$ identifies as K-states on the basis of manner modification data, is actually to be characterised as a group of concepts with relatively poor conceptual substructure. It has already been pointed out that restrictions on manner modification cannot be used as an argument against a neo-Davidsonian analysis of states, because these two issues are orthogonal. We are now left with the question of whether the results of the conceptual model of modification are at least compatible with the claim of sortal differences.

One thing that casts doubt on having a sortal distinction between two types of statives is that it predicts a clear-cut dichotomy. The analysis of modifiers (e.g. with bright / shine / gleam) does not support such a dichotomy. The considerations in section 3.3 rather suggest that between "static" and "dynamic" concepts there is a grey area of concepts variously involving "dynamic potentials". It is not clear that all such concepts can uniformly be analysed as eventdenoting and as being in contrast to nondynamic concepts. Deciding this point has to be left for future work, though.

Moreover, we are still not in a position to provide a clean definition of what is a manner adverb and what is not, although, of course, the claim that (certain) statives do not allow manner modification would require such a definition. This problem similarly applies to the work of Katz (2003), who likewise maintains that statives do not have Davidsonian arguments, and who proposes that all modifiers of statives might be explained away as predicate operators, instead of being neo-Davidsonian predicates. From my perspective, this distinction is not so clear-cut. In a way, I have sketched a view in which all kinds of manner modification are reduced to operations on predicates; but this only concerned the level of conceptual analysis, not semantic composition in the clause. My account could be implemented in Logical Form either as composition via predicate operators or via Davidsonian predication. In an extensional, neo-Davidsonian representation, a manner adverb 
would appear as a context-sensitive property of events. This is to say, adverbial modifiers, defined via a set of property values as in (19) above can always be mapped onto a set of events, i.e. a neo-Davidsonian predicate of events. The template $\operatorname{MANNER}_{(\mathbf{C})}(\mathrm{A})$ (for a modifier $\mathrm{A}$ in the context of an event predicate $\mathrm{C}$ ) would then represent a lexical operation that shifts an adjective A, initially a predicate of some other sort of entities, to a predicate of events, in a way which is sensitive to the meaning of $\mathrm{C}$. Then, the neo-Davidsonian representations of the modifiers would not reflect their underlying lexical-conceptual format; rather, the neo-Davidsonian semantics for manner modification would have to be seen as a purely compositional device. (This position has already been expressed in Geuder 2000).

In spite of the continuing uncertainty as to the precise delimitation of manner modification, one of the positive results of the present work is that a conceptual definition of "manner modification" is at least within reach. Still, we have various options as to how we can define a class of "manner adverbs" from the background of conceptual structures:

- Variant 1: Manner $=$ "Modifiers that restrict some conceptual dimension of a multidimensional concept (a predicate of category V?)"

This is the most liberal way of defining manner. It would create a minimal contrast between hell rot "brightly red" (more than one dimension, hence "manner") and angenehm hell "pleasantly bright" (scalar adjective, hence no "manner"). Usually, however, all subsective modifiers of nouns would also be excluded from the class of "manner modifiers", in spite of well-known semantic parallels between many noun and verb meanings; and I have never seen the term "manner" applied to adjectives. It also remains unclear whether all subsective modifiers of verbs should be included.

- Variant 2: Manner = "Modifiers that restrict some conceptual dimension of an eventdenoting predicate"

The distinction sounds intuitively appealing, but, evidently, it begs the question as to which predicates denote events! The definition probably creates minimal pairs like: hell leuchten "shine brightly" (manner) vs. hell rot "brightly red", but it would not contribute to an understanding of the difference.

- Variant 3: Manner = "Modifiers that restrict an eventive type of conceptual dimension"

In this way, not all subsective modifiers of verbs, but only those addressing change-ofstate concepts or continuation conditions (etc.) inside a verbal concept would qualify as manner modifiers. This begins to appear overly strict, as it would characterise friedlich schlafen "sleep peacefully" as manner modification, but exclude the type hell leuchten "shine brightly".

Probably, "manner modification", while not devoid of content, is going to remain a notion without sharp boundaries. All in all, then, I conclude that the facts about manner modification point to a continuum between eventive and stative concepts, and that manner modification cannot be reduced to matters of Logical Form and predication of Davidsonian arguments.

\section{References}

Barsalou, L.: 1992, Frames, Concepts, and Conceptual Fields, in A. Lehrer \& E. Kittay (eds), Frames, Fields, and Contrasts. Hillsdale NJ: Erlbaum, pp. 21-74

Davidson, D.: 1967, The logical form of action sentences, in N. Rescher (ed), The Logic of Decision and Action, Pittsburgh: The University of Pittsburgh Press, pp. 81-95 
Geuder, W.: 2000, Oriented Adverbs. Issues in the Lexical Semantics of Event Modifiers, doctoral dissertation, Universität Tübingen. (Universität Tübingen online publication service: http://w210.ub.uni-tuebingen.de/dbt/volltexte/2002/546/ )

Geuder, W.: 2004, Depictives and Transparent Adverbs, in J. Austin, S. Engelberg \& G. Rauh (eds), Adverbials. The Interplay between Meaning, Context and Syntactic Structure. Amsterdam: Benjamins, pp. 131-166.

Geuder, W. \& Weisgerber, M.: 2005, On the Geometrical Representation of Concepts. Ms. Universität Konstanz.

Katz, G.: 2000, Anti neo-Davidsonianism: against a Davidsonian semantics for state sentences, in C. Tenny \& J. Pustejovsky (eds), Events as Grammatical Objects, CSLI Publications, 393-414

Katz, G.: 2003, Event arguments, adverb selection, and the Stative Adverb Gap, in E. Lang, C. Maienborn \& C. Fabricius-Hansen (eds): Modifying Adjuncts, Berlin: Mouton de Gruyter, pp. 455-474

Kim, J.: 1976, Events as Property Exemplifications, in M. Brand \& D. Walton (eds), Action Theory. Proceedings of the Winnipeg Conference on Human Action, Dordrecht: Reidel, pp. 159-177.

Maienborn, C.: 2004 (Ms., forthcoming), On Davidsonian and Kimian states, To appear in I. Comorowski \& K. v. Heusinger (eds), Existence: Semantics and Syntax. Berlin: Springer.

Maienborn, C.: 2005, On the Limits of the Davidsonian Approach: The Case of Copula Sentences (Target Article), Theoretical Linguistics 31-3, 275-316

Parsons, T.: 1990, Events in the Semantics of English, Cambridge MA: MIT Press.

Stamm, H.: 2005, On the Semantics of Gradation of Verbs. Talk presented at "Sinn \& Bedeutung X", Berlin, Humboldt University, October 15, 2005 